\title{
Experimental Study of Solar-Assisted Heating System
}

\author{
Jieting Wei ${ }^{1}$, Yang $\mathrm{Liu}^{2}$, Yu Gu ${ }^{2}$ \\ ${ }^{1}$ Changchun Institute of Technology,Changchun,China \\ ${ }^{2}$ Northeast Dianli University,Jilin,China \\ Email: 191420465@qq.com
}

Received May, 2013

\begin{abstract}
Solar heating is a new energy saving technology. This paper studies the operating characteristics of solar-assisted heating system in Changchun area, the changes of the indoor temperature with the conditions of solar-assisted heating system .By analyzing these operating data we can see solar-assisted heating to meet the requirements of the indoor temperature and save energy.
\end{abstract}

Keywords: Solar; Assisted Heating; Energy Saving

\section{Introduction}

Solar heating is the most potential solar thermal utilization technology after solar heating the water, it should be popularized in the future. With the state has increased the use of renewable energy, and unveiled preferential policies, solar heating technology has an extensive application prospect [1]. As regards the present situation, there is a wide range of markets for solar energy in our country, but correlation study is still lacking, the lack of relevant data, so the experimental build a solar-assisted heating bench, finishing the test data, provided the basis for data for the practical application of solar-assisted heating engineering.

At present, the terminal device for most of the solar heating system are used radiant floor heating, however, terminal devices of most of the existing residential buildings are radiators, so this paper studies solar assisted radiator heating system.

\section{The Experiment of Solar-assisted Heating System}

In an energy-efficient building, selected a $58 \mathrm{~m}^{2}$ room as an experimental room, and selected another room as the comparison room that the size, towards and maintenance structure are the same with the experimental room. According to calculation the heating load of the experimental room is $3480 \mathrm{~W}$.The experimental system uses the Huayang vacuum tube solar water heater, collector area is 3.83 , the tank capacity is $250 \mathrm{~L}$. The system is lack of elevated water tank, not able to meet the conditions of the natural cycle (solar energy can be used as an elevated water tanks, the reason for it can not natural cycle is that the heat source and the heat dissipation center can not formed the height difference). Therefore, there is a $290 \mathrm{w}$ miniature pump in the system as a cycle power, the suction inlet of the pump is connected heat source, the direction of flow: heat source $\rightarrow$ pump $\rightarrow$ radiator.

The experimental procedure is as follows: solar collector absorbs solar radiation, transforms it into heat energy stored in the storage tank for room heating, and composes of a set of sola- assisted heating system with the end of the heat dissipation device.

There are four long airfoil radiators, two intelligent temperature control strong convection radiators, two radiators through the valve can series parallel used, and can run separately, so that can satisfy the requirements of different indoor temperature. In summer, when the indoor temperature is too high, to pass the tap water into the intelligent temperature control strong convection radiators, after heat transfer treatment sending cold air to the room to eliminate waste heat, similar to the role of a simple split air-conditioning, to maintain the temperature of the interior cool. In winter, under normal circumstances, only use the long airfoil radiator heating to meet the requirements of indoor temperature, when outdoor temperature mutation or fluctuations in a very obvious situation can be appropriate to open the intelligent temperature control strong convection radiators, to ensure that the interior parameters are maintained within the desired temperature range. By two radiators combined operation (forced convection heat transfer and natural convection heat transfer) is sufficient to meet the heating requirements of the room.

Data collection included the supply water temperature of radiator $t_{1}$, the return water temperature of radiator $t_{2}$, indoor temperature of the heating roomt $_{3}$, indoor temperature of the non-heating room $t_{4}$, outdoor air temper- 
ature $t_{5}$, wind speed $v$, solar radiation intensity.

Heating system as illustrated below.

\section{Experimental Data and Analysis}

There are two cases of the experiment: one for fine weather, sunny, without opening the auxiliary heating device will be able to meet the basic needs of the interior; Another situation is the rainy weather, lacking of intensity of solar radiation, the need to open the auxiliary heating equipment to meet the basic needs of the interior. Now analysis the test data results of both cases.

Experimental results and analysis are as follows

\subsection{Experimental Data and Analysis without Auxiliary Heating Equipment}

Figure 2 shows contrast curves of the indoor temperature of the heating room, indoor temperature of the nonheating room and outdoor air temperature. Table 1 lists the peak point on the curve. From above, it can be seen that the trend of the indoor and outdoor temperature is substantially same. The average temperature of the heating room is $22 . .23^{\circ} \mathrm{C}$, and the average temperature of the non-heating room is $18.52^{\circ} \mathrm{C}$. The average temperature of the heating room is higher than the non-heating room $1.1^{\circ} \mathrm{C} \sim 5.7^{\circ} \mathrm{C}$.

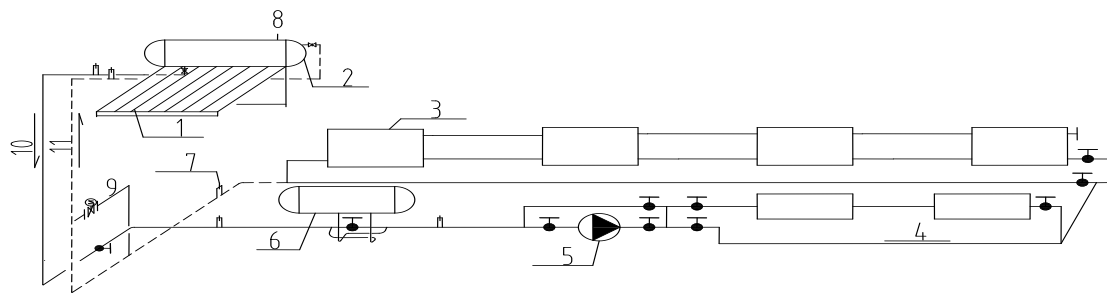

Figure 1. The system diagram of the solar-assisted heating.

Table 1. The equipments name of the solar-assisted heating system.

\begin{tabular}{clcc}
\hline 1 & \multicolumn{1}{c}{ Solar collectors } & 7 & Temperature Sensor Placement \\
\hline 2 & Heat Storage Water Tank & 8 & Water Overflow Port \\
3 & Long Airfoil Radiator & 9 & Connect Tap Water \\
4 & Intelligent Temperature Control Strong Convection Radiator & 10 & Heating supply water \\
5 & Circulating Water Pump & 11 & Heating return water \\
6 & Electric Heater & & \\
\hline
\end{tabular}

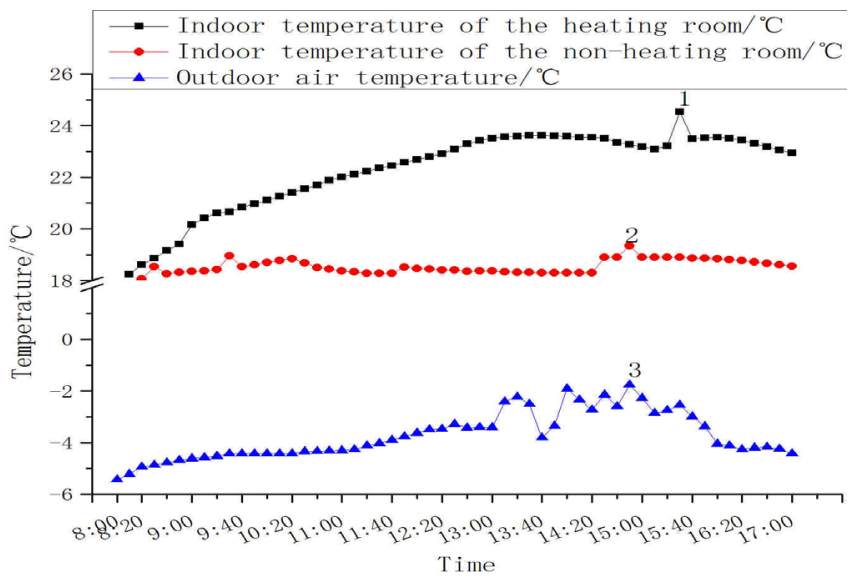

Figure 2. The comparison chart of indoor and outdoor temperature.

Table 2.

\begin{tabular}{ccc}
\hline & X Axis $($ Time $)$ & Y Axis $\left(\right.$ Temperature $\left./{ }^{\circ} \mathrm{C}\right)$ \\
\hline 1 & $15: 20$ & 24.62 \\
2 & $14: 50$ & 19.34 \\
3 & $14: 50$ & -1.35 \\
\hline
\end{tabular}


Figure 3 shows contrast curves of the radiator supply and return water temperature and heating load. Table 2 shows the supply and return water temperature on the curve, the peak point of heating load. The loading heat $\mathrm{Q}$ is calculated after measured system flow rate.

$$
\mathrm{Q}=\mathrm{CM} \Delta \mathrm{T} / \mathrm{KW}
$$

According to the formula (1) the loading heat of radiator is calculated. We can educe that the trend of the radiator supply and return water temperature is broadly similar. The average temperature difference of the radiator supply and return water temperature is $7^{\circ} \mathrm{C} \sim 10^{\circ} \mathrm{C}$.

Figure 4 shows the contrast curves of the radiator supply and return water temperature and solar radiation intensity. Table 1 lists the maximum value of solar radiation intensity and radiator supply and return water temperature. This shows that the trend of the radiator supply and return water temperature and solar radiation intensity is broadly consistent. The peak of the radiator supply and return water temperature delay compared to the intensity of solar radiation, which is caused due to the regenerative properties of the water tank.

Figure 5 shows comparison graph of the indoor and outdoor temperature, loading heat. Table 4 lists the maximum worth of indoor temperature of the heating room, indoor temperature of the non-heating room, outdoor air temperature and the loading heat of the heating room. This shows that when the outdoor temperature is high, the room temperature and loading heat to obtain the maximum.

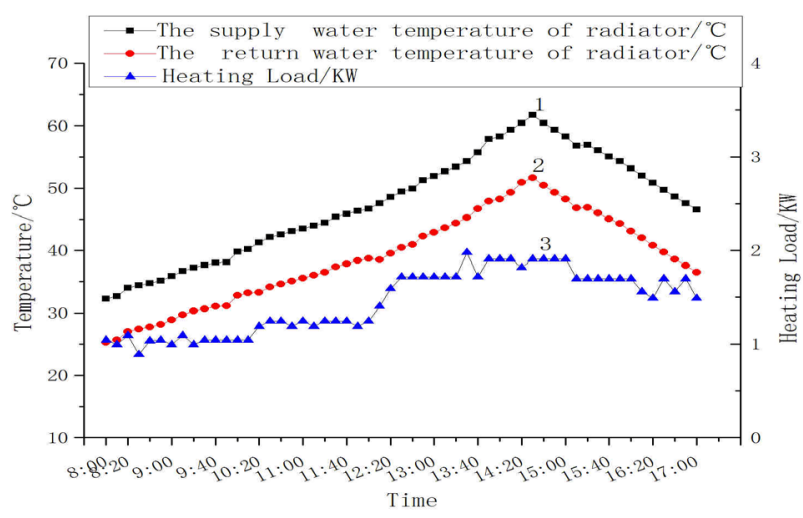

Figure 3. The comparison chart of radiator supply and return water temperature and heating load.

Table 3.

\begin{tabular}{ccc}
\hline & X Axis $($ Time $)$ & Y Axis $\left(\right.$ Temperature $\left./{ }^{\circ} \mathrm{C}\right)$ \\
\hline 1 & $14: 30$ & 61.679 \\
2 & $14: 30$ & 51.679 \\
3 & $15: 00$ & $1.9087($ Heating Load $/ \mathrm{KW})$ \\
\hline
\end{tabular}

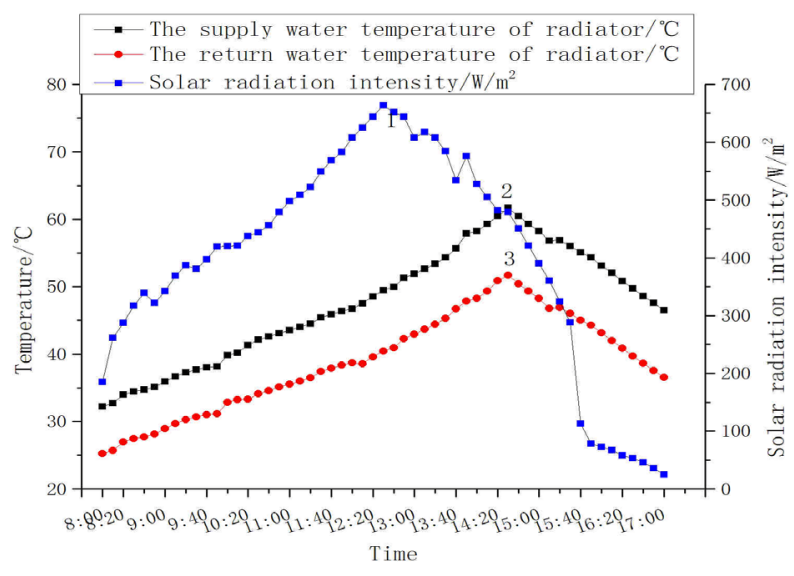

Figure 4. The comparison chart of radiator supply and return water temperature and solar radiation intensity.

Table 4.

\begin{tabular}{ccc}
\hline & X Axis $($ Time $)$ & Y Axis $\left(\right.$ Temperature $\left./{ }^{\circ} \mathrm{C}\right)$ \\
\hline 1 & $12: 30$ & $664\left(\right.$ solar radiation intensity $\left./ \mathrm{W} / \mathrm{m}^{2}\right)$ \\
2 & $14: 30$ & 61.679 \\
3 & $14: 30$ & 51.679 \\
\hline
\end{tabular}

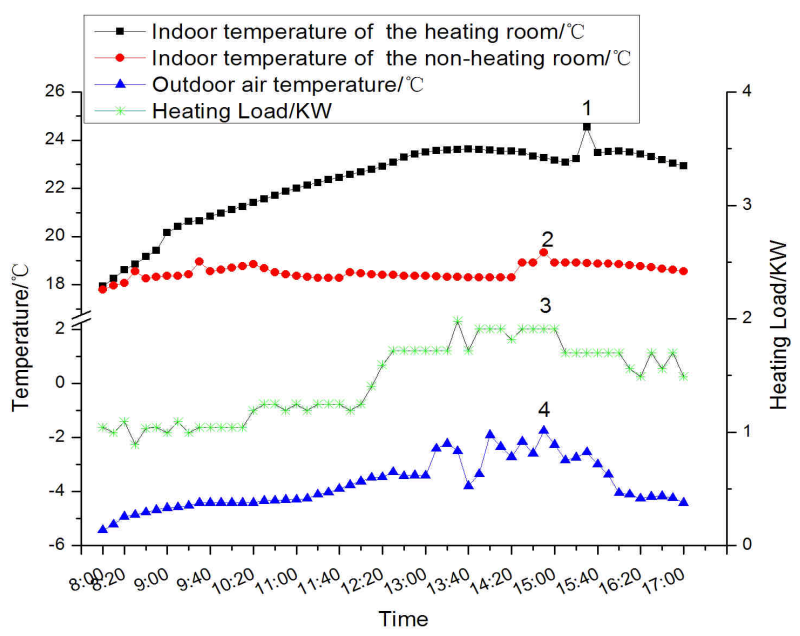

Figure 5. The comparison chart of indoor and outdoor temperature and heating load.

Table 5.

\begin{tabular}{ccc}
\hline & X Axis (Time) & Y Axis $\left(\right.$ Temperature $\left./{ }^{\circ} \mathrm{C}\right)$ \\
\hline 1 & $15: 30$ & 24.539 \\
2 & $14: 50$ & 19.335 \\
3 & $15: 00$ & $1.9087($ Heating Load/KW $)$ \\
4 & $14: 50$ & -1.75 \\
\hline
\end{tabular}




\subsection{Experimental Data and Analysis with Auxiliary Heating Equipment}

Figure 6 shows the contrast curve of the radiator supply and return water temperature and heating load when opening the electric heater. Opened the electric heater at 8:00, closed it after one hour. It reached a small peak of the radiator supply and return water temperature and heating load at 9:00.After that it operated independently rely on solar radiation .Opened the electric heater auxiliary heating again at 15:00 pm, closed it after one hour. It reached a small peak again at 16:00, but with the electric heater was turned off, all the value were gradually reduced. The value all showed in Table 5 .

Figure 7 shows comparison chart of radiator supply and return water temperature and solar radiation intensity when opening the electric heater. Table 6 shows the value of each point. Opened the electric heater at 8:00, closed it after one hour. The solar radiation was strongest and radiator supply and return water temperature reached the maximum value at 11:20. With the intensity of solar radiation, the supply and return water temperature gradually weakened, Turned on the electric heater again for one hour at 15:00. Thus, the radiator supply and return water temperature is controlled by the intensity of solar radiation.

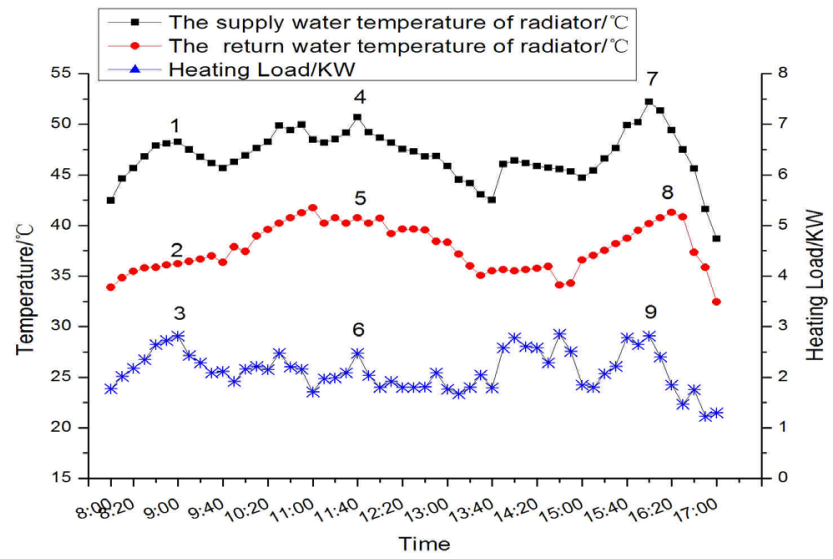

Figure 6. The comparison chart of radiator supply and return water temperature and heating load when opening the electric heater.

Table 6.

\begin{tabular}{|c|c|c|c|c|c|}
\hline & 9:00 & & $11: 40$ & & $16: 00$ \\
\hline & Y Axis (Temperature $/{ }^{\circ} \mathrm{C}$ ) & & Y Axis (Temperature $/{ }^{\circ} \mathrm{C}$ ) & & Y Axis(Temperature $/{ }^{\circ} \mathrm{C}$ ) \\
\hline 1 & 48.265 & 4 & 50.695 & 7 & 52.203 \\
\hline 2 & 36.226 & 5 & 40.734 & 8 & 40.156 \\
\hline 3(Heating Load) & $2.8164 \mathrm{KW}$ & 6(Heating Load) & $2.4694 \mathrm{KW}$ & 9(Heating Load) & $2.8182 \mathrm{KW}$ \\
\hline
\end{tabular}

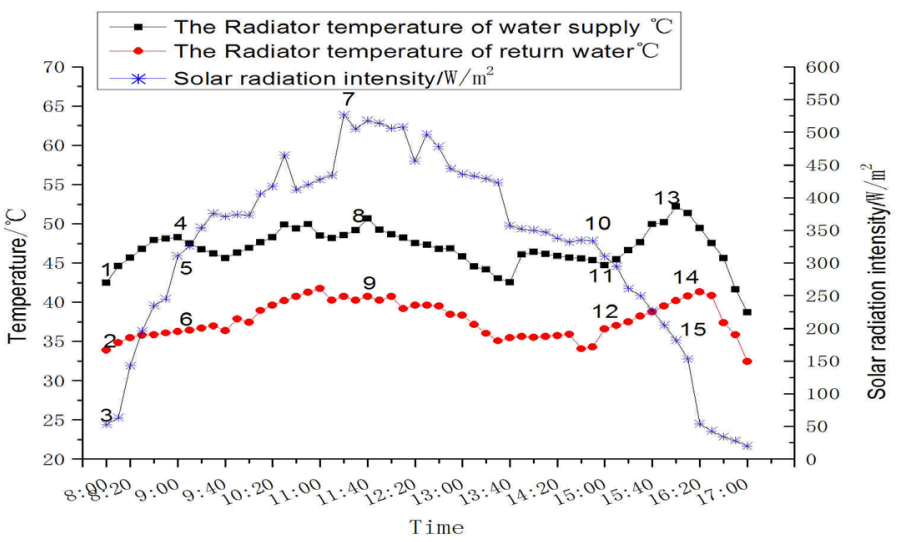

Figure 7. The comparison chart of radiator supply and return water temperature and solar radiation intensity when opening 
the electric heater.

Table 7.

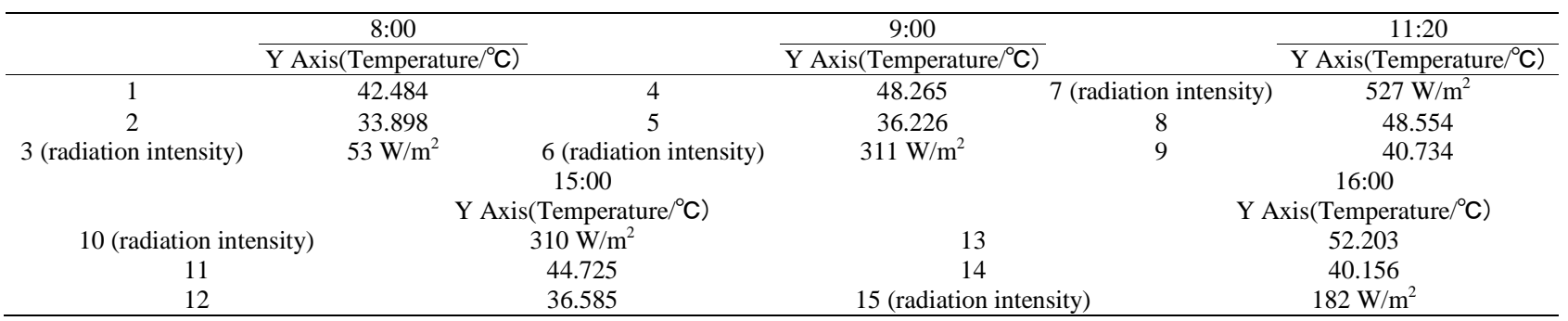

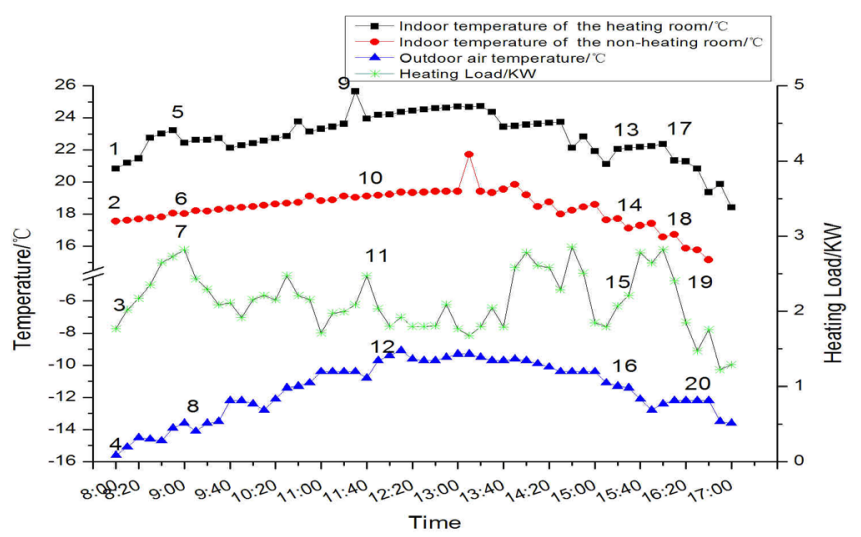

Figure 8. The comparison chart of indoor and outdoor temperature and heating load when opening the electric heater.

Table 8.

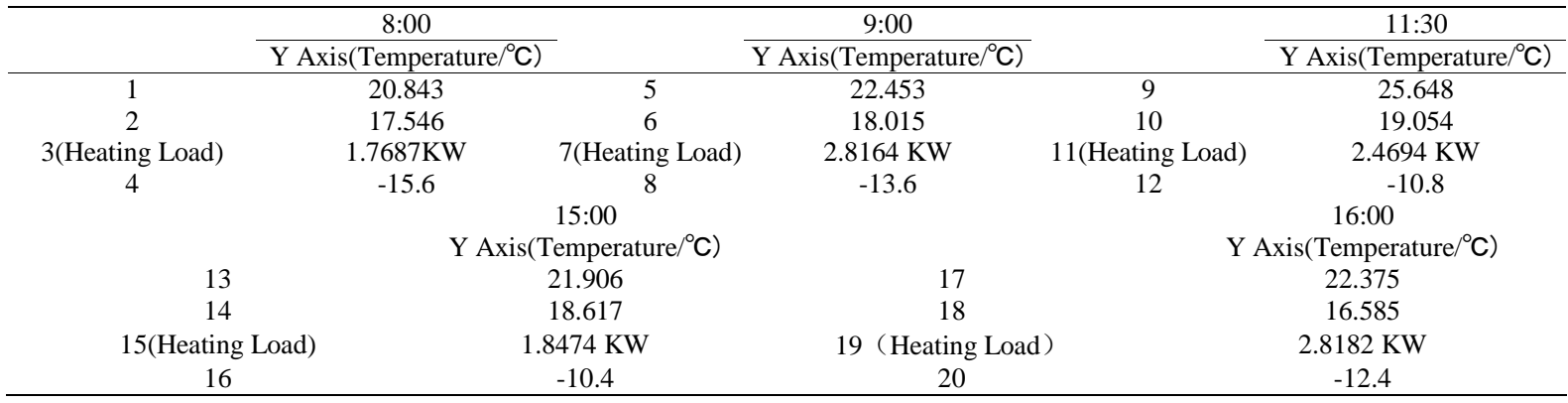

Figure 8 shows comparison chart of the indoor and outdoor temperature and heating load when opening the electric heater. Table 7 respectively lists the value of each point. From the graph can be seen, opening the electric heater can increased significantly the room temperature and the heating load, the temperature can improve an average of $1^{\circ} \mathrm{C} \sim 2^{\circ} \mathrm{C}$. This shows, the effect of the solar- assisted heating system is common decision by the solar radiation intensity and the outdoor temperature

\section{Energy Saving Quantity of the Solar-assisted Heating System}

Take $40 \%$ solar fraction, the number of heating period in Changchun is 170 days, heating load of The room is $3480 \mathrm{~W}$. Thus the heating load for one day is $3480 \times$ $24 / 1000=83.52 \mathrm{Kwh}=300.67$ MJ. Thus the total ener- gy saving quantity is $\mathrm{Q}=40 \% \times 170 \times 300.67=$ 20445.56 MJ = 4891 Mcal. The heat of the definition of standard coal in China is $7000 \mathrm{kcal} / \mathrm{kg}$ (7 Mcal/kg). Therefore a heating season can save standard coal: 698 $\mathrm{kg}$. There will be a huge contribution to energy conservation.

\section{Conclusions}

By the above experiments and the collation of data, we can see that the use of solar-assisted heating in Changchun is feasible and have a certain effect. The solar collector area of the experimental system is $3.83 \mathrm{~m}^{2}$, the room area is $58 \mathrm{~m}^{2}$, in the case of Changchun region sunshine, the rise of the room temperature can reach $4^{\circ} \mathrm{C}$, and thus see, in energy-efficient buildings $1 \mathrm{~m}^{2}$ solar collectors as an auxiliary heating can heat $15 \mathrm{~m}^{2}$ room. 
Through the experiment, conclusions are drawn as follows:

1) Solar-assisted heating can meet the temperature requirements of room, the average temperature of the heating room reaches $22^{\circ} \mathrm{C}$ on average higher than nonheating room $4^{\circ} \mathrm{C}$

2) The operating results of the solar-assisted heating system by the solar radiation, the outdoor temperature as so on. The system supply and return temperature difference maintain in $7^{\circ} \mathrm{C}$.

3) In energy-efficient buildings, the proportion of solar collector area and room area is1:15.

4) Changchun area belongs to the area of solar energy resources are abundant, solar heating is both environmentally friendly and energy conservation, research should be focused.

\section{REFERENCES}

[1] Z. N. He and D. Z. Zhu, "Solar Heating Application Manual,” Beijing: Chemical Industry Press, 2009. 